\title{
Spenders versus savers: climate-induced carbon allocation tradeoffs in an introduced woody plant
}

\author{
Randy Long ${ }^{1}$, Tom Dudley ${ }^{1}$, Carla D’Antonio ${ }^{1}$, Kevin $_{\text {Grady }}^{2}$, Susan E. Bush ${ }^{3}$, and Kevin \\ Hultine $^{3}$ \\ ${ }^{1}$ University of California Santa Barbara \\ ${ }^{2}$ Northern Arizona University \\ ${ }^{3}$ Desert Botanical Garden
}

November 18, 2020

\begin{abstract}
Non-structural carbohydrate (NSC) storage may be under strong selection in woody plant species that occur across strong environmental gradients. We therefore investigated carbon allocation strategies in a widely distributed, introduced woody plant. We predicted genotypes from cold climates with exposure to episodic freeze events, would have elevated NSC concentrations with the tradeoff of reduced growth and reproduction relative to warm-adapted genotypes. We established an experimental common garden using genotypes of Tamarix spp., sourced across a large thermal gradient within their introduced range. We measured seasonal NSC storage in coarse roots and stems, above-ground growth and flower production. Autumn NSC concentrations were $50 \%$ higher in genotypes from sites with spring freeze events compared to genotypes from warmer sites. Cold-adapted genotypes also had a 2.3-fold higher starch to soluble sugar ratio than warm-adapted genotypes. Across all genotypes and seasons, NSC storage was inversely correlated with growth and reproduction. Results suggest that Tamarix from colder locations cope with freeze events by maintaining large storage pools to support tissue regrowth, but with the tradeoff of reduced growth and reproduction. Results provide evidence of selection in carbon allocation strategies in response to climate in introduced woody species.
\end{abstract}

\section{Hosted file}

Long_title_page.pdf available at https://authorea.com/users/376798/articles/493674-spendersversus-savers-climate-induced-carbon-allocation-tradeoffs-in-an-introduced-woody-plant

\section{Hosted file}

Long_PCE_main_text.pdf available at https://authorea.com/users/376798/articles/493674spenders-versus-savers-climate-induced-carbon-allocation-tradeoffs-in-an-introducedwoody-plant 


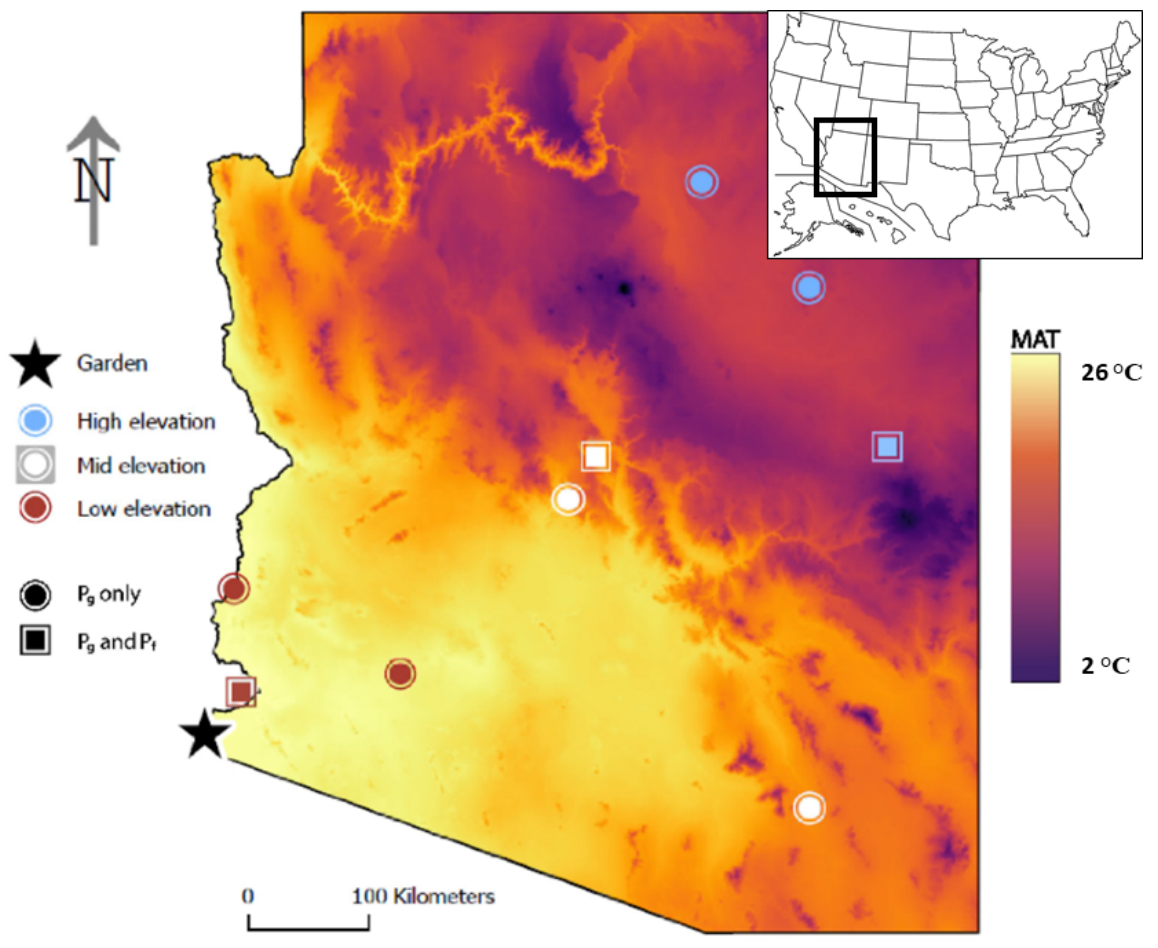



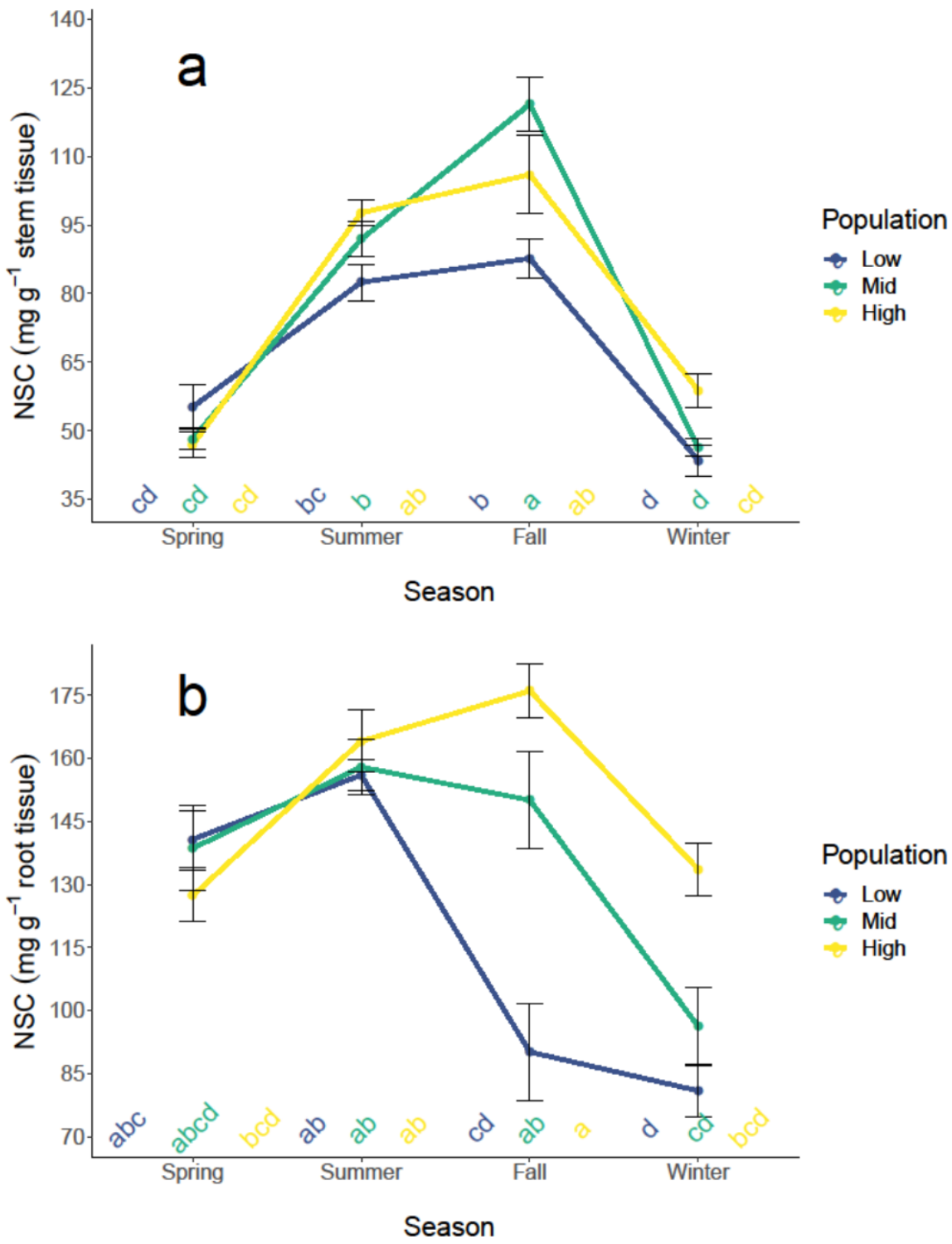

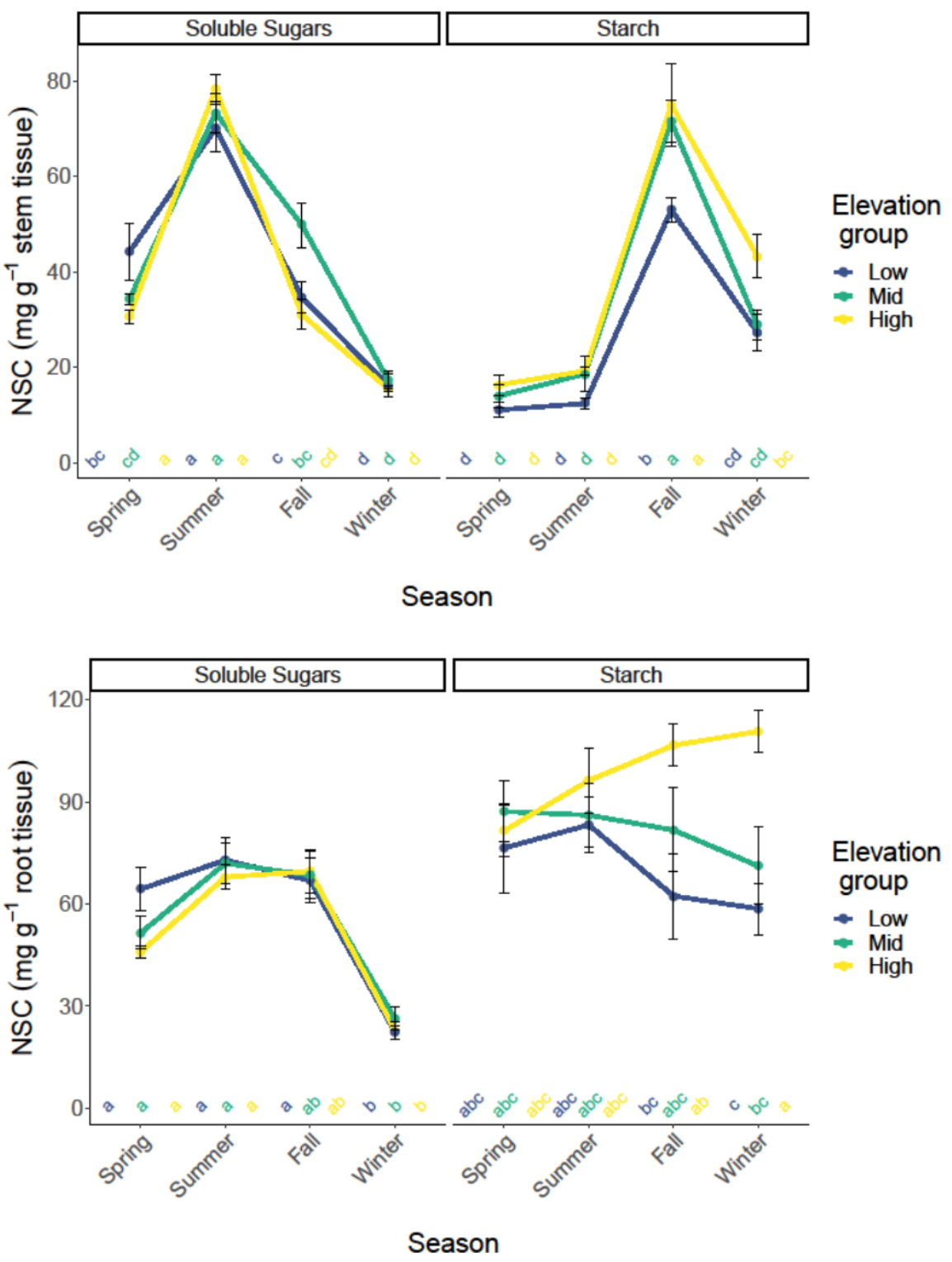

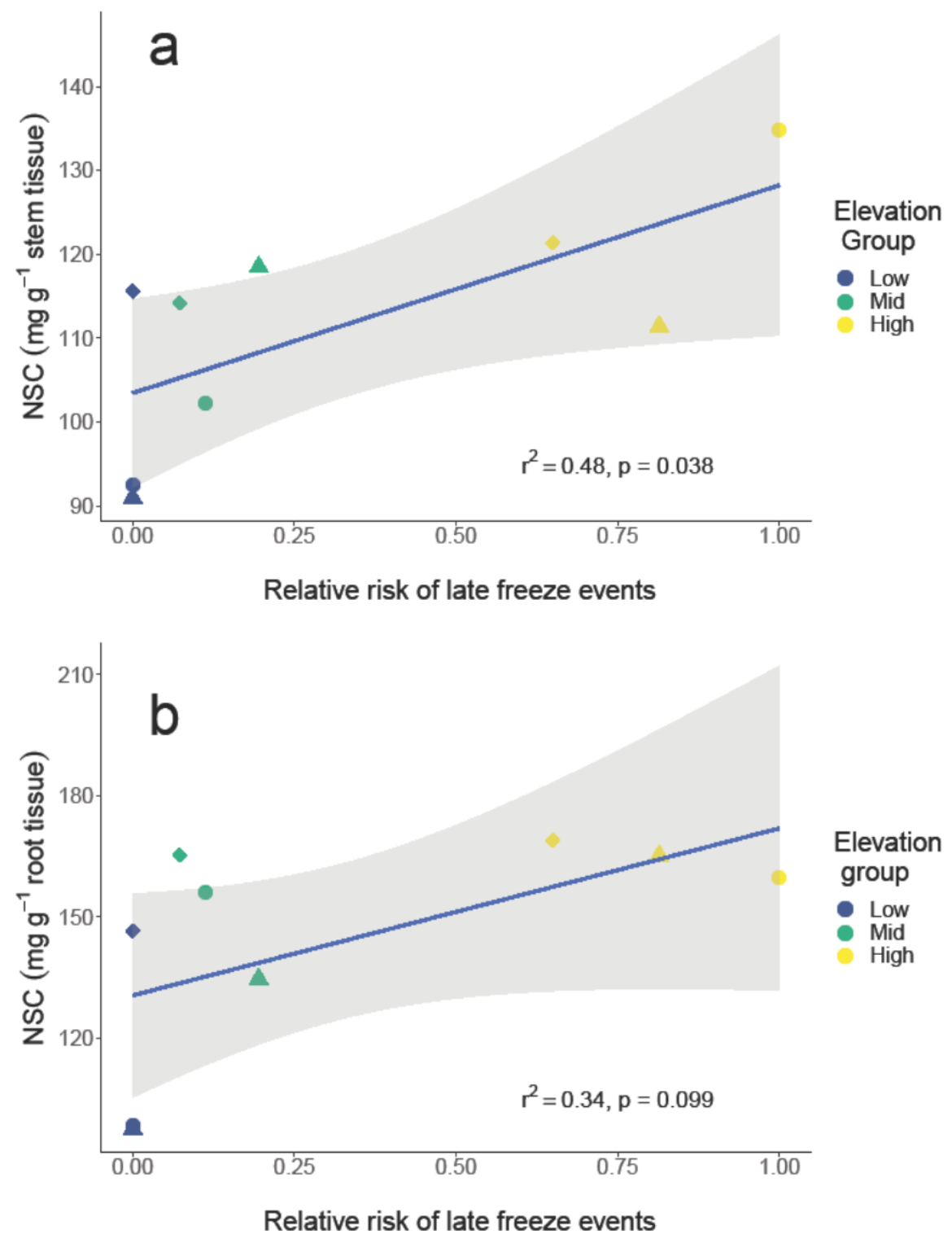


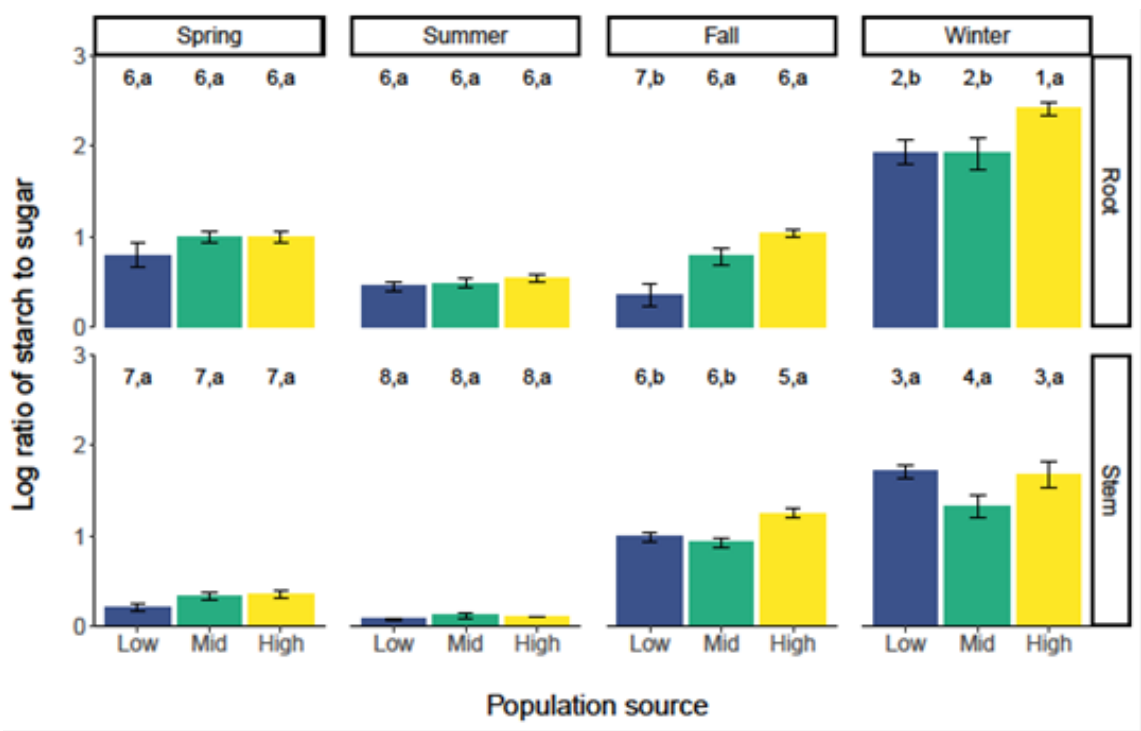



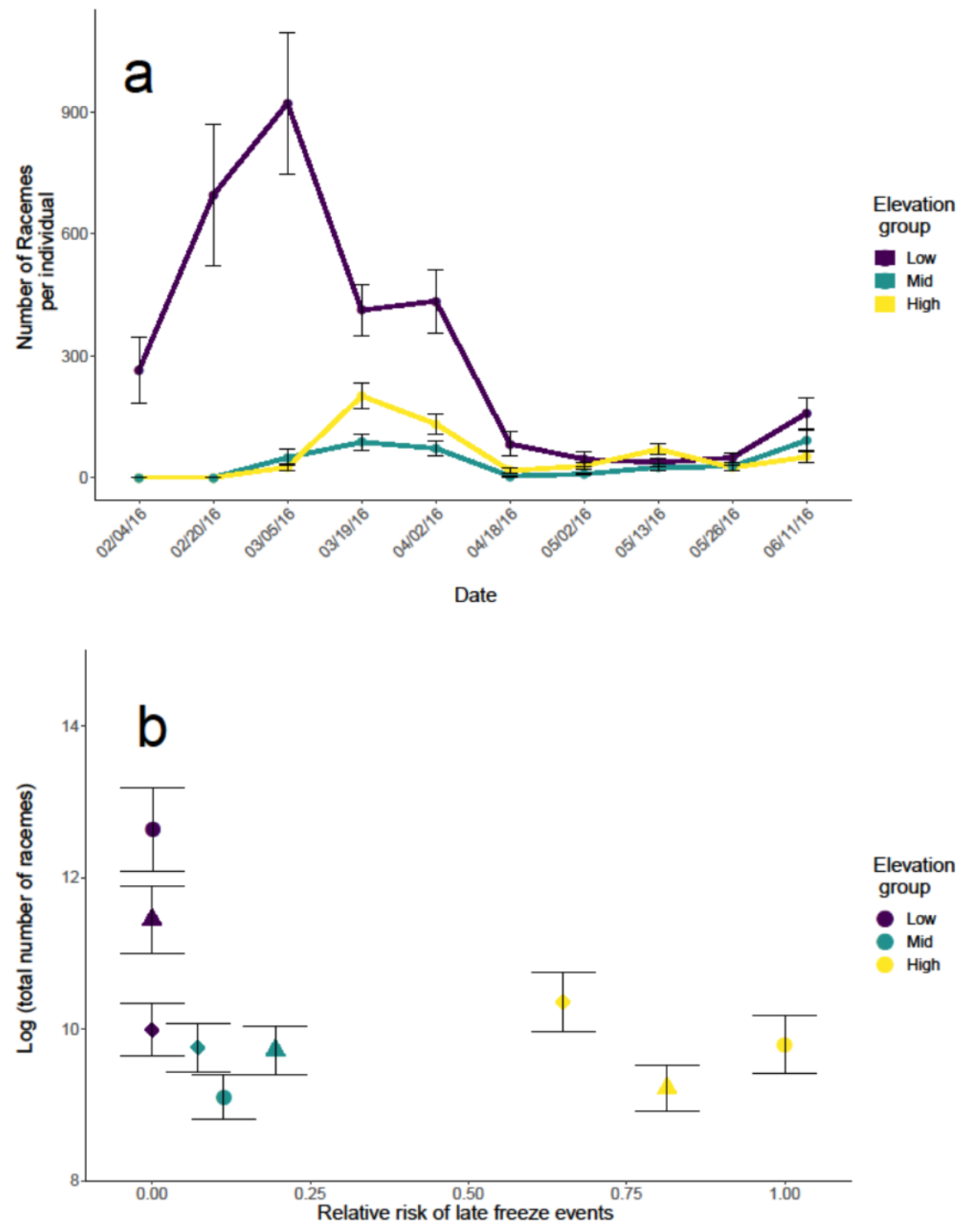


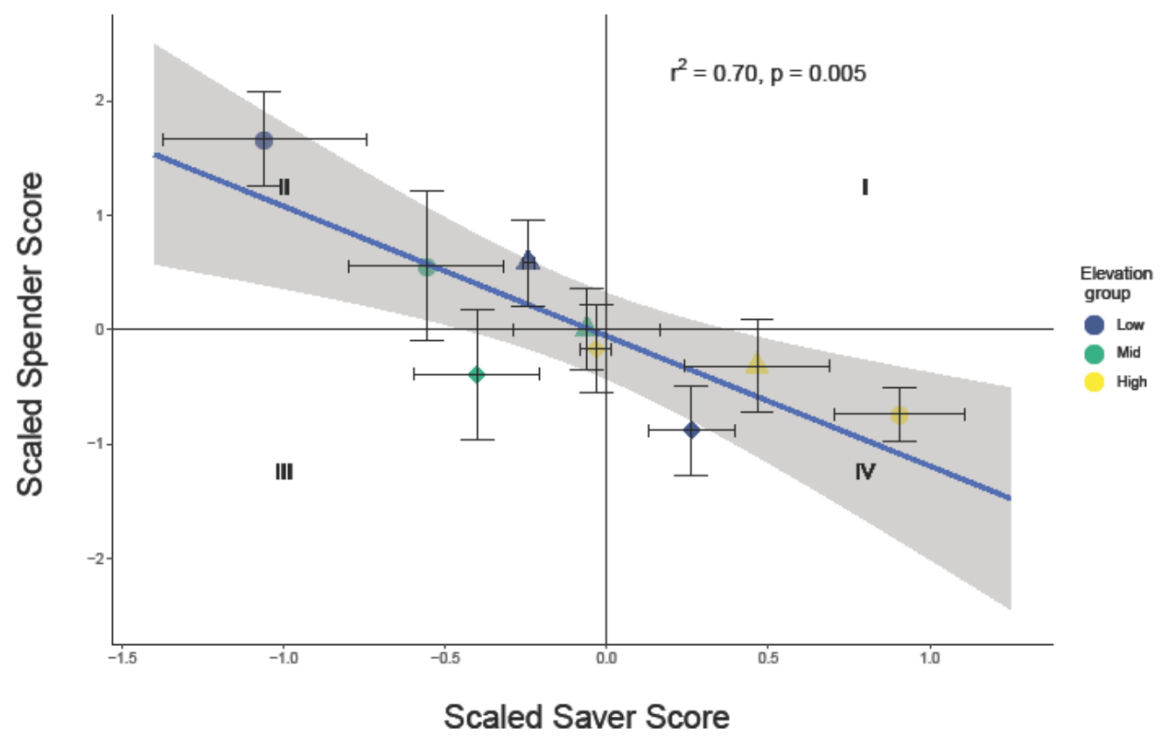

